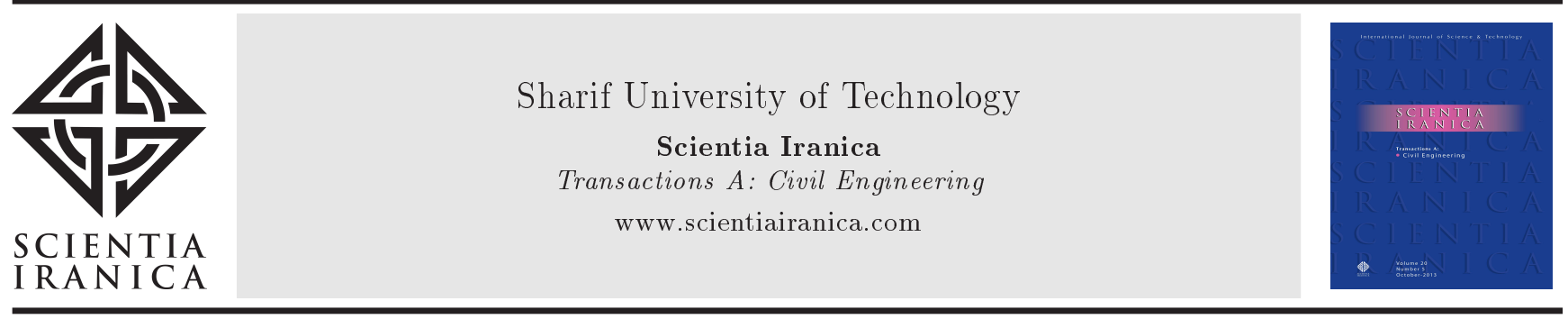

Research Note

\title{
Effects of moisture on warm mix asphalt containing Sasobit
}

\author{
H. Nabizadeh ${ }^{a}$, B. Naderi ${ }^{\mathrm{b}, *}$ and N. Tabatabaee ${ }^{\mathrm{c}}$ \\ a. Department of Civil and Environmental Engineering, University of Nevada, Reno, NV. \\ b. Department of Civil and Environmental Engineering, Tarbiat Modares University, Tehran, Iran. \\ c. Department of Civil Engineering, Sharif University of Technology, Tehran, P.O. Box 11555-9313, Iran.
}

Received 7 January 2015; received in revised form 24 October 2015; accepted 11 April 2016

\author{
KEYWORDS \\ Warm mix asphalt; \\ Sasobit; \\ Moisture \\ susceptibility; \\ Hydrated lime; \\ Tensile strength ratio; \\ Toughness; \\ Fracture energy.
}

\begin{abstract}
The asphalt industry has been at the forefront of sustainable development. Warm Mix Asphalt (WMA) has been developed to cope with issues such as high energy prices and air pollution. These mixes require less energy and generate fewer pollutants during production in comparison with conventional Hot Mix Asphalt (HMA). Although a promising technology, the durability of WMA is not clear because long-term WMA field performance data is limited. This study investigated the susceptibility of Sasobit-modified WMA to moisture, since moisture damage is a major cause of premature pavement failure in asphalt concrete. To this end, WMA samples were made using different concentrations of Sasobit and the results were compared with those from HMA mixtures. The effect of hydrated lime as an anti-stripping agent was also investigated. The tensile strength ratios indicate that the introduction of hydrated lime and Sasobit increased the resistance of asphalt mixtures to moisture. Fracture energy and toughness were used to evaluate the crack resistance of specimens under dry and wet conditions. In comparison with Sasobit, hydrated lime increased crack resistance of mixtures. The results indicate that hydrated lime can be used as a compatible and effective anti-stripping agent for WMAs containing Sasobit.
\end{abstract}

(C) 2017 Sharif University of Technology. All rights reserved.

\section{Introduction}

Sustainable development in pavement construction calls for new approaches to the design, construction, and maintenance of pavement systems that require large amounts of material, energy, and investment. The asphalt industry has incorporated reclaimed asphalt pavement and other industrial by-products and waste materials into asphalt during the past few decades [1]. Over the last decade, Warm Mix Asphalt (WMA) tech-

*. Corresponding author.

Fax: +982166014828

E-mail addresses: hnabizadeh@unr.edu (H. Nabizadeh

Shahri); b_naderi@alum.sharif.edu (B. Naderi);

nader@sharif.edu (N. Tabatabaee) nology has emerged, which lowers greenhouse gas emissions, reduces exposure of workers to asphalt fumes, and minimizes the use of natural resources [2]. This innovative technology significantly reduces the mixing and compaction temperatures of asphalt mixtures by lowering the viscosity of asphalt binders during mix production [3]. The biggest challenge is to produce durable mixtures while minimizing environmental concerns.

WMA production includes the use of organic additives, foaming, and chemical additives [3,4]. Sasobit is an organic additive extensively used for WMA. It is produced using the Fischer-Tropsch process from coal gasification and can be mixed directly with the binder or blown into the drum [5]. This organic additive forms a homogeneous solution with the base binder 
and reduces the binder viscosity at temperatures above $115^{\circ} \mathrm{C}[6,7]$. Sasobit reduces mixing and handling temperatures by $10-30^{\circ} \mathrm{C}$, significantly reducing the emission of asphalt binder fumes and $\mathrm{CO}_{2}[6,7]$; however, below its melting point, Sasobit tends to increase binder stiffness [8].

Although WMA has received considerable attention over the past decade, its in-service performance properties are not clearly known. The NCHRP Project 09-43 evaluated the volumetric properties of WMA and HMA mixtures and concluded that those properties were similar when binder absorption did not exceed $1.0 \%$. Their research indicated that the coating, compactability, moisture sensitivity, and rutting resistance of WMA mixtures might differ from those of HMA mixtures of the same composition and that WMA was highly affected by the process and temperature [9].

The most premature distress that affects asphalt pavement performance relates to moisture damage. The detrimental effects of water cause loss of strength and durability in asphalt mixtures [10,11]. Moisture damage occurs due to loss of adhesion (water leaking into the asphalt-aggregate system and stripping away the asphalt film) and cohesion (softening of asphalt concrete mastic) $[10,11]$. Although the lower mixing temperatures in WMA technology reduce emissions and energy consumption, they can adversely affect the aggregate drying process and cause moisture-induced damage. Foaming uses steam as a means to reduce the viscosity of the binder, but the water trapped in the coated aggregate can cause damage $[12,13]$. Although wax does not release water into the asphalt mixture, because it increases lubrication of the binder, uncertainty exists about chemical reactions occurring between the aggregate, binder, and wax $[12,13]$.

A number of additives are available that mitigate moisture sensitivity of asphalt mixtures. These treatments can be introduced directly to the asphalt binder as a modifier or can be applied to the aggregate [14]. Hydrated Lime (HL) is the most commonly-used anti-stripping agent that decreases moisture susceptibility [15]. HL makes the migration of $\mathrm{Ca}^{++}$to the aggregate surface reacting with carboxylic acid and 2-quinolone groups in asphalt binder to form insoluble salts. These reactions facilitate strong bonding between asphalt binder and the aggregate surface. In addition, the presence of deleterious materials such as clay on the aggregate is inevitable, and the pozzolanic reaction of hydrated lime flocculates the materials that cover the aggregate surface $[11,14,15]$.

This study evaluates the moisture susceptibility of HMA and WMA mixtures modified with HL and Sasobit by employing the conventional TSR method [16], and the concept of facture and toughness energy.

\section{Research objectives and methodology}

The present study investigated the effects of hydrated lime and Sasobit on the moisture susceptibility of asphalt mixtures. HMA samples modified with HL and WMA samples containing different concentrations of Sasobit were made and tested. The samples and control HMA samples were tested using AASHTO T 283 standards for moisture susceptibility. To accommodate different moisture conditions for each type of mixture, six samples with $7 \pm 0.5 \%$ were divided into two subsets, dry and wet, in such a way that the average air voids for two subsets were approximately equal. A total of 48 samples were made. Table 1 outlines the experimental design for this research.

\section{Materials and testing}

\subsection{Materials}

Sasobit is a long-chain aliphatic hydrocarbon which melts at $115^{\circ} \mathrm{C}$ that reduces binder viscosity. After crystallization, it forms a lattice structure that becomes the basis of the structural stability of the binder. To create homogenous WMA binders for testing, Sasobit was melted by heating to $120^{\circ} \mathrm{C}$ and then added to the binder in a low shear mixer (350 rpm) at $135^{\circ} \mathrm{C}$ and mixed for $10 \mathrm{~min}$. The concentrations tested were $1.5 \%, 2.5 \%$, and $3.5 \%$ (wt) of the base binder. A PG 64-22 asphalt binder from Tehran refinery was used. Binders were graded in accordance with AASHTO M320 and the results are shown in Table 2 .

Modification of the binder with Sasobit resulted in higher complex moduli and phase angles compared

Table 1. Experimental design of mixtures used in this study.

\begin{tabular}{cccc}
\hline Mixture & Acronyms & $\begin{array}{c}\text { No. of } \\
\text { levels }\end{array}$ & Description of levels \\
\hline HMA & Control, HL\% & 4 & No additive (control) \\
& & & $1 \%, 1.5 \%$, and $2 \%$ HL \\
WMA & Saso\% & 4 & $1.5 \%, 2.5 \%$, and $3.5 \%$ Sasobit \\
& & & $1.5 \%$ Sasobit $+1.5 \%$ HL \\
\hline
\end{tabular}


Table 2. Superpave performance grading for asphalt binders.

\begin{tabular}{|c|c|c|c|c|}
\hline \multirow[b]{2}{*}{ Specimen } & \multicolumn{3}{|c|}{ Continuous grade $\left({ }^{\circ} \mathrm{C}\right)$} & \multirow[b]{2}{*}{$\begin{array}{c}\text { Performance } \\
\text { Grade (PG) }\end{array}$} \\
\hline & $\begin{array}{c}\text { High } \\
\text { temperature }\end{array}$ & $\begin{array}{l}\text { Intermediate } \\
\text { temperature }\end{array}$ & $\begin{array}{c}\text { Low } \\
\text { temperature }\end{array}$ & \\
\hline Neat & 65.2 & $19.8(22)$ & -23.7 & $64-22$ \\
\hline Saso $1.5 \%$ & 70.0 & $24.5(25)$ & -17.1 & $70-16$ \\
\hline Saso $2.5 \%$ & 73.5 & $26.5(28)$ & -14.5 & $70-10$ \\
\hline Saso $3.5 \%$ & 74.9 & $27.3(28)$ & $<-10$ & $70-06$ \\
\hline
\end{tabular}

Table 3. Physical properties of aggregate.

\begin{tabular}{cccc}
\hline Test & ASTM standard & Measured value & Limit \\
\hline Bulk specific gravity (coarse agg.) & $\mathrm{C} 127-01$ & 2.683 & - \\
Bulk specific gravity (fine agg.) & $\mathrm{C} 128-01$ & 2.687 & - \\
Los Angeles abrasion & $\mathrm{C} 131-01$ & $12 \%$ & Max $45 \%$ \\
Coarse aggregate angularity & $\mathrm{D} 5821-95$ & $96 \%$ & Min $90 \%$ \\
Flat and elongated particles & $\mathrm{D} 4791-99$ & $5.5 \%$ & Max $10 \%$ \\
Water absorption (\%) & $\mathrm{C} 127, \mathrm{C} 128$ & $>1 \%$ & - \\
\hline
\end{tabular}

to the control binder, which can be attributed to the formation of Sasobit crystals [8,17]. These effects can be associated with a better performance at high temperatures, but cause brittleness at low temperatures; however, discussing this complex interaction solely on the basis of rheological analysis without consideration of morphology and the microstructure of Sasobit modification is not a reasonable approach. It should be noted that investigation of chemical binder-Sasobit reactions is not the objective of this study.

Table 3 shows the physical properties of the aggregate. Aggregate gradation with a nominal maximum size of $19 \mathrm{~mm}$ was used in accordance with AASHTO MP 2, as shown in Figure 1.

Table 4 shows the chemical composition of the

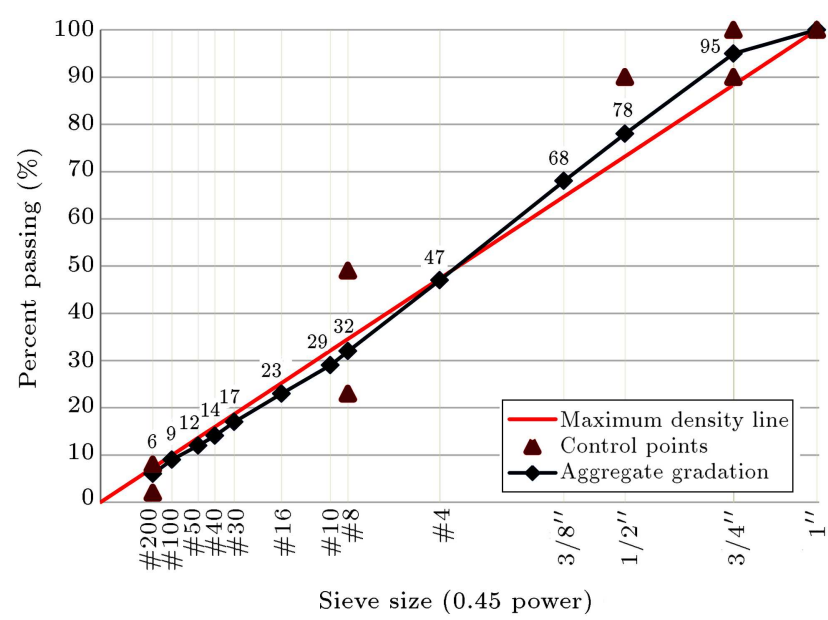

Figure 1. Aggregate gradation with $19 \mathrm{~mm}$ nominal maximum size.
Table 4. Chemical composition of hydrated lime.

\begin{tabular}{ccc}
\hline Chemical composition & $\begin{array}{c}\text { Measured } \\
\text { value }\end{array}$ & Limit \\
\hline Calcium and magnesium oxides & $90 \%$ & Min $90 \%$ \\
Carbon dioxide & $3 \%$ & Max $50 \%$ \\
Hydrated calcium and magnesium & $3 \%$ & Max 5\% \\
$\quad$ oxides & & Max 2\% \\
Free moisture of dry hydrates & 0 &
\end{tabular}

passing \#200 HL used in accordance with ASTM C1097-01. There are several methods for introducing HL into an asphalt mixture. Here, HL slurry was added to the dry aggregate and the lime-treated aggregate was then marinated for $24 \mathrm{~h}$ prior to preparation of specimens.

\subsection{Mix design}

Appropriate temperatures for mixing and compaction correspond to viscosity ranges of $0.17 \pm 0.02 \mathrm{~Pa} . \mathrm{S}$ and $0.28 \pm 0.03$ Pa.s, respectively, in accordance with AASHTO T 312. NCHRP Report 691 demonstrated that the true temperature of WMA processes was not merely a matter of the relationship between viscosity and temperature; the coating, workability, and compatibility of mixtures should also be evaluated in preliminary trial specimens [5]. Considering the mentioned parameters, the mixing and compaction temperatures for WMA mixtures were $135^{\circ} \mathrm{C}$ and $125^{\circ} \mathrm{C}$ and for HMA were $150^{\circ} \mathrm{C}$ and $140^{\circ} \mathrm{C}$, respectively.

Specimens were made in accordance with AASHTO R 35. Aggregates were heated to $10^{\circ} \mathrm{C}$ above mixing temperature for $3 \mathrm{~h}$ prior to specimen 
fabrication to eliminate undesirable moisture content. Because binder absorption was less than $1 \%$, the volumetric properties of the WMA and HMA mixtures were almost the same [5]. The optimum binder content was $5.5 \%$ (wt of aggregate) for the control HMA mixture and $5.3 \%$ for the WMA mixture, although the addition of HL lowered the binder content to $5 \%$ for all mixtures.

\subsection{Test methods}

The resistance of compacted bituminous mixtures to moisture-induced damage was measured in accordance with AASHTO T 283. Six specimens with $7.0 \pm$ $0.5 \%$ air voids were made; the first three specimens remain unconditioned and the other three were subjected to vacuum saturation of $70 \%$ to $80 \%$ (degree of saturation). Afterwards, the vacuum-saturated samples were conditioned in a $60^{\circ} \mathrm{C}$ water bath for $24 \mathrm{~h}$ and then all samples were submerged in a $25^{\circ} \mathrm{C}$ water bath for $2 \mathrm{~h}$ to achieve a constant temperature prior to testing. During the test, the load was applied along the diameter of the specimens at a constant rate of $50 \mathrm{~mm} / \mathrm{min}$ vertical deformation until failure.

The parameters measured were Indirect Tensile Strength (ITS), Tensile Strength Ratio (TSR), fracture energy to failure $\left(\Gamma_{f a}\right)$, Fracture Energy Ratio (FER), Toughness (T), and Toughness Ratio (TR). ITS (kPa) is expressed as:

$$
\mathrm{ITS}=\frac{2000 \times P}{\pi . t . d}
$$

and TSR (\%) is expressed as:

$$
\mathrm{TSR}=\frac{\text { ITS }_{\mathrm{wet}}}{\text { ITS }_{\mathrm{dry}}} \times 100,
$$

where $P$ is the maximum vertical load applied $(\mathrm{kN}), t$ is the average height of the specimen $(\mathrm{m})$, and $d$ is the average diameter of the specimen $(\mathrm{m})$.

Figure 2 shows $\Gamma_{f a}$ (N.m), which is defined by Witczak et al. [16] as the area under the load vertical deformation curve up to deformation incurred at maximum load for both dry and wet samples. FER (\%) can be expressed as:

$$
\mathrm{FER}=\frac{\Gamma_{\text {fawet }}}{\Gamma_{\text {fadry }}} \times 100 .
$$

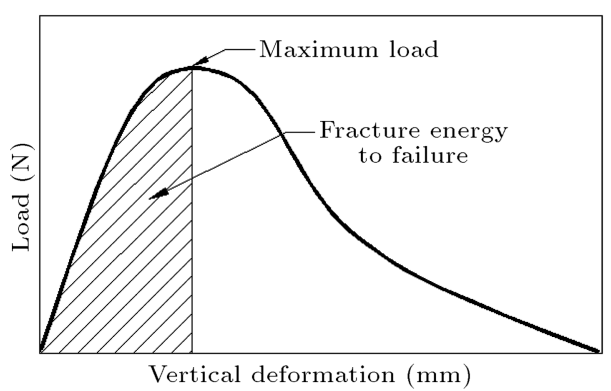

(a)
$T(\mathrm{~N} / \mathrm{mm})$, as shown in Figure 2, is defined as the area under the ITS deformation curve up to a deformation of twice that incurred at maximum tensile stress [18]. TR $(\%)$ is expressed as:

$$
\mathrm{TR}=\frac{T_{\mathrm{wet}}}{T_{\mathrm{dry}}} \times 100 .
$$

\section{Results and discussion}

\subsection{ITS analysis}

The minimum TSR is 0.80 as specified in AASHTO M 323. A comparison of TSR values with the minimum acceptable value may not be sufficient; some recent studies [10,19] specify an additional criterion for a minimum value for wet ITS and a minimum TSR. Figure 3 shows the results for TSR and Figure 4 shows the results for ITS. All wet ITS results were well above the limit $448 \mathrm{kPa}$ (65 psi), indicating that minimum TSR was the governing criterion.

The ITS and TSR of the control HMA mixtures were the lowest. WMA samples were more resistant to the detrimental effects of moisture conditioning than the control HMA, but not as resistant as HL-treated HMA. Increasing the Sasobit content slightly increased the TSR. This can be attributed to the effect of Sasobit lattice structure on increasing binder stiffness and the use of fully-dried aggregates. The bond between aggregate and binder can be negatively affected by the existence of moisture in aggregates during production of asphalt mixtures. To prevent this, the aggregates were preheated for $3 \mathrm{~h}$ to eliminate any undesirable moisture and the results were satisfactory. WMA mixing and compaction temperatures were well above the Sasobit melting point, ensuring that the aggregate was fully coated. Moreover, the high angularity and rough surface texture of the aggregates resulted in better aggregate interlock leading to high tensile strength.

The addition of $1 \%$ HL produced a $16 \%$ change in the TSR of the control sample, indicating that HLtreated specimens meet the proposed criteria. The TSR slightly increased as the HL content increased from $1 \%$ to $2 \%$. Note that the total filler content of mixtures was constant; consequently, HL replaced a

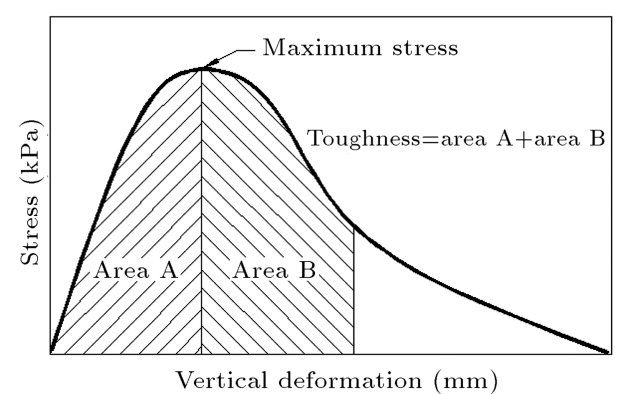

(b)

Figure 2. Schematic presentation of (a) fracture energy to failure [16], and (b) toughness [18]. 


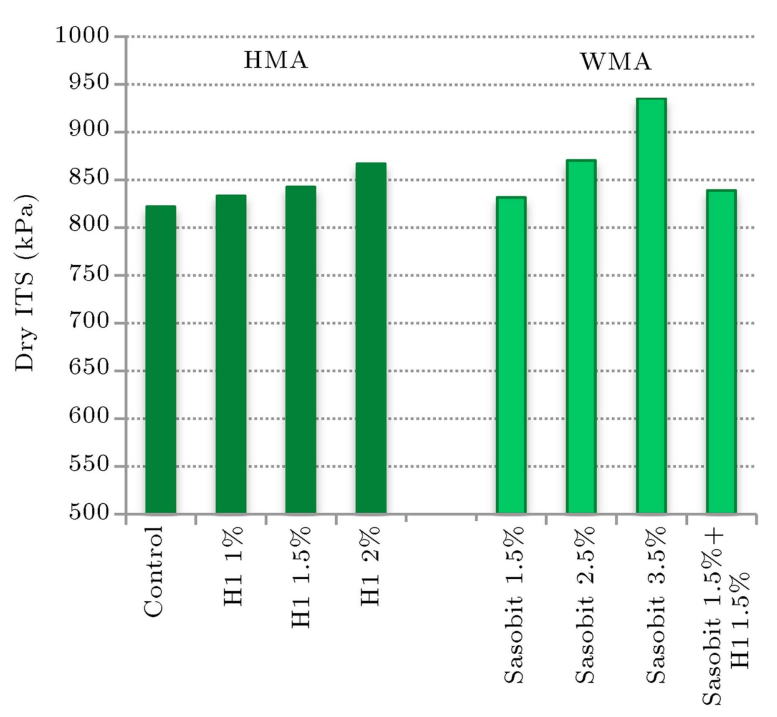

(a)

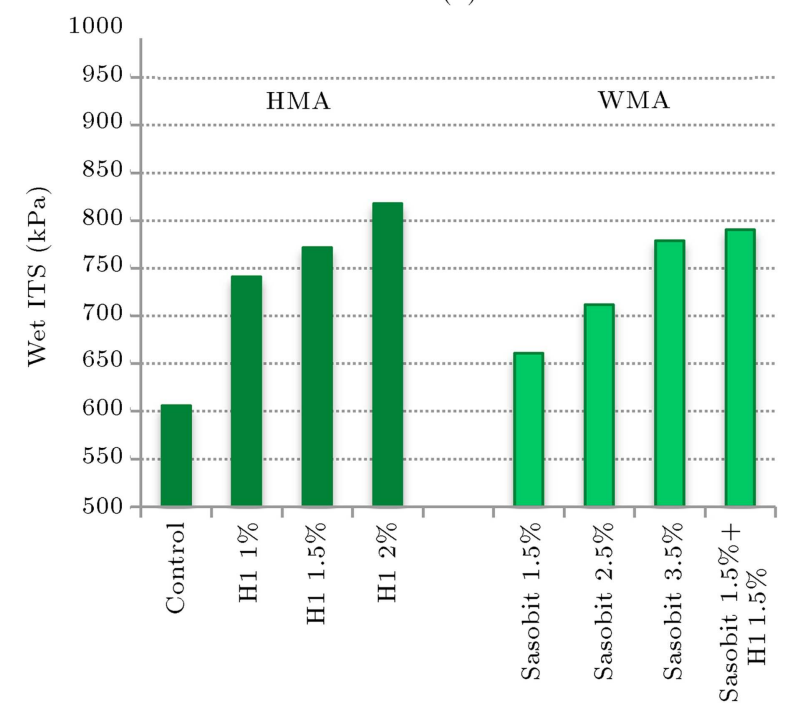

(b)

Figure 3. Results of (a) dry ITS, and (b) wet ITS.

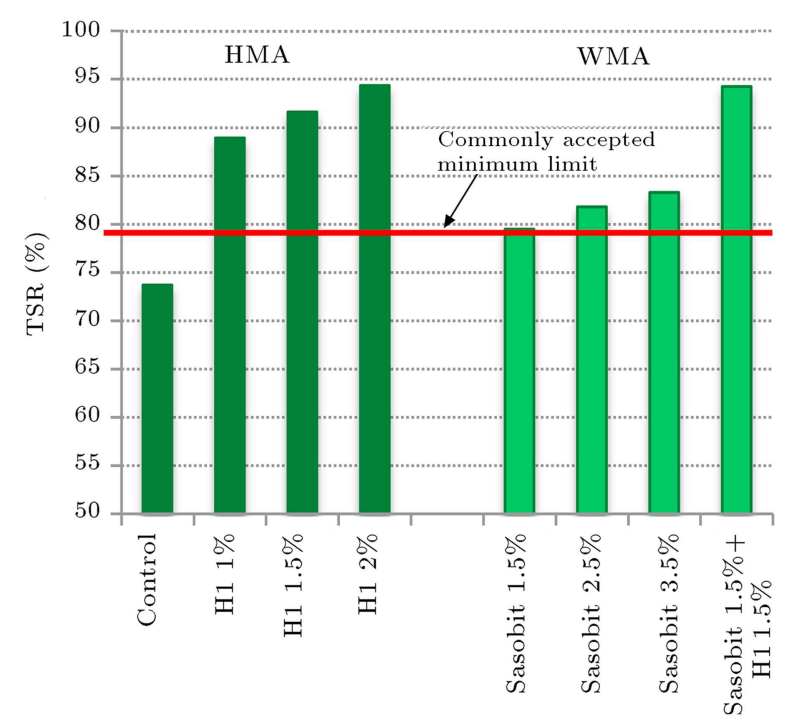

Figure 4. TSR results for HMA and WMA. part of the aggregate filler. This result allows better understanding of the effects of HL on the aggregatebinder bond in the presence of water.

Although the minimum acceptable TSR value is $80 \%$ for most agencies, the WMA samples with TSRs ranging from $79.5 \%$ to $84.5 \%$ only show marginal performance. This indicates that the use of anti-stripping agent is necessary. To overcome this deficiency, WMA mixtures were made with $1.5 \%$ Sasobit (wt of base binder) and the aggregate was treated with $1.5 \% \mathrm{HL}$ (wt of aggregates). This resulted in a significant increase in the TSRs, making them comparable to those for HMA with $2 \% \mathrm{HL}$.

\subsection{Fracture energy analysis}

The energy absorbed up to the point of failure (fracture energy) calculated using the IDT strength test is an excellent indicator of the resistance of mixtures to cracking and of the fact that higher fracture energy values correspond to higher cracking resistance [18]. Fracture energy analysis considers both the stress and strain results of the test. Figure 5 shows that the mixtures treated with HL had greater dry and wet fracture energies than the control HMA mixtures. This indicates a greater capacity to absorb the mechanical work induced by repeated tire loading on pavement $[18,20]$.

Unlike the ITS and TSR values, the fracture energy of WMA mixtures was less than that of the control HMA mixtures. Modification of WMA samples with HL increased the dry and wet fracture energies. The FER in Figure 6 shows that WMA samples responded similarly to the control HMA and the HLtreated WMA behaved similarly to the HL-treated HMA.

\subsection{Toughness analysis}

Similar to fracture energy analysis, toughness analysis relates to the energy absorbed in the IDT strength test. Figure 7 shows the dry and wet toughness values. It is evident that the mixtures containing WMA additives generally produce lower toughness values than the control mixture, which can be attributed to the lower deformation of WMA samples as a result of crystallization of Sasobit wax. Although the Sasobit content increased the tensile strength of the samples, their strain resistance decreased as the binder stiffness increased, which decreased the calculated fracture energy.

Figure 8 shows the TR and indicates that there was no significant improvement in moisture susceptibility of WMA mixtures compared with control HMA samples. It is evident that the TR increased in limetreated mixtures of HMA and WMA. 


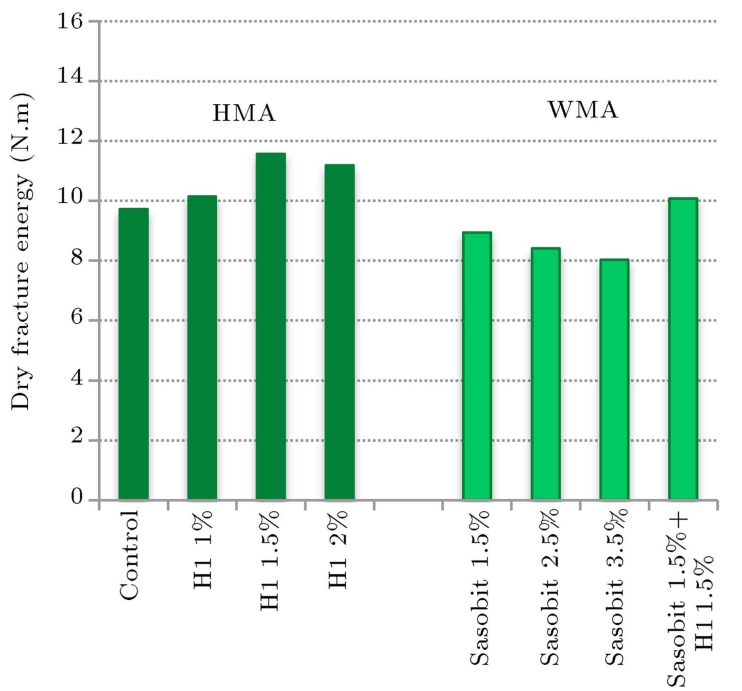

(a)

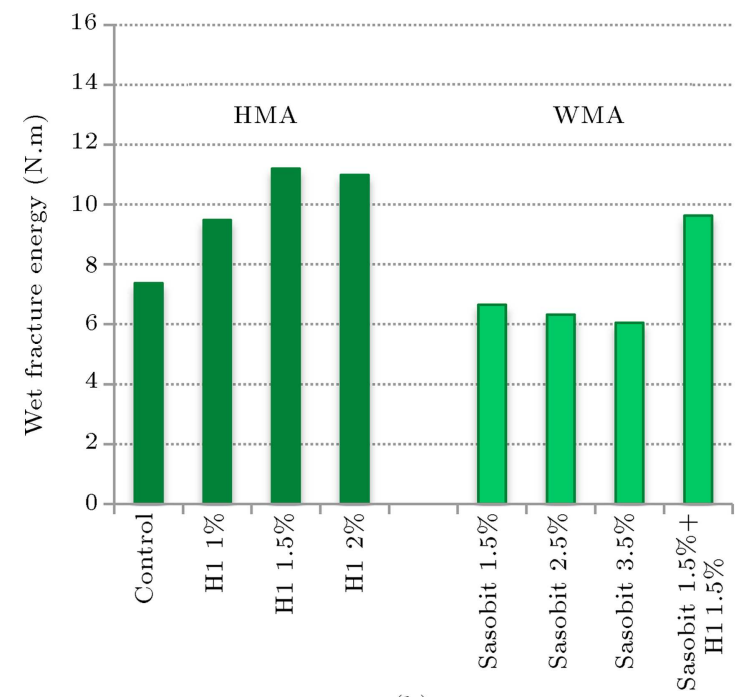

(b)

Figure 5. Results for (a) dry fracture energy, and (b) wet fracture energy.

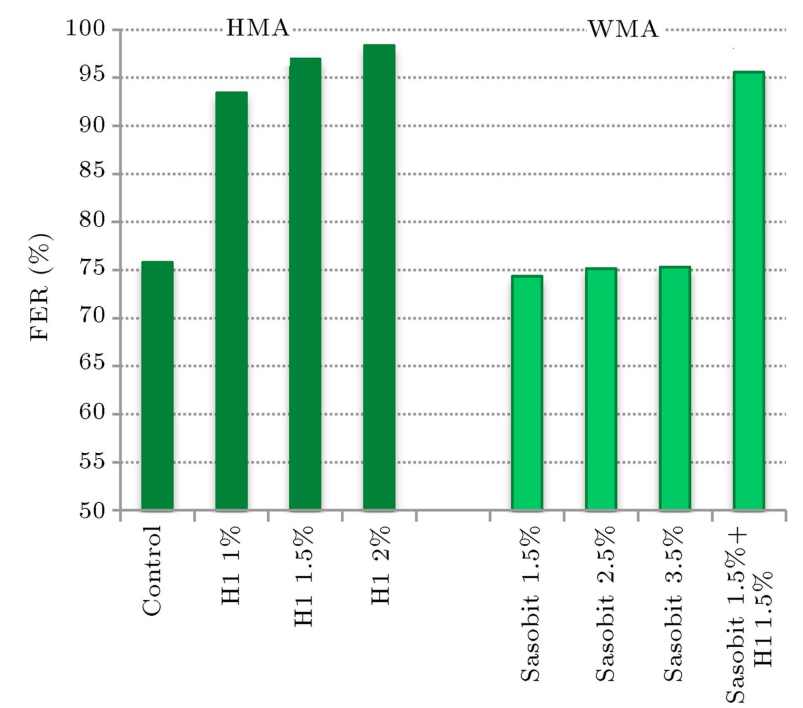

Figure 6. FER results for HMA and WMA.

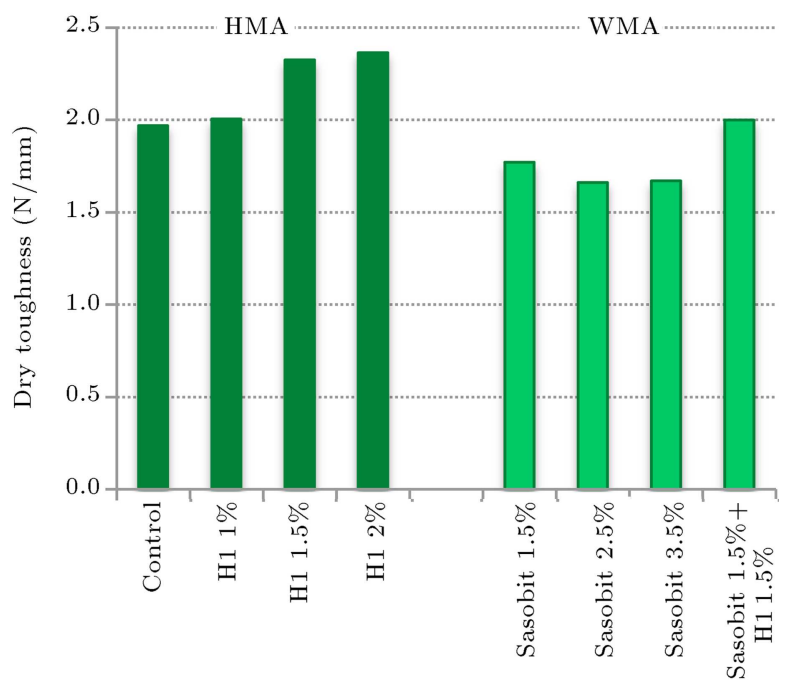

(a)

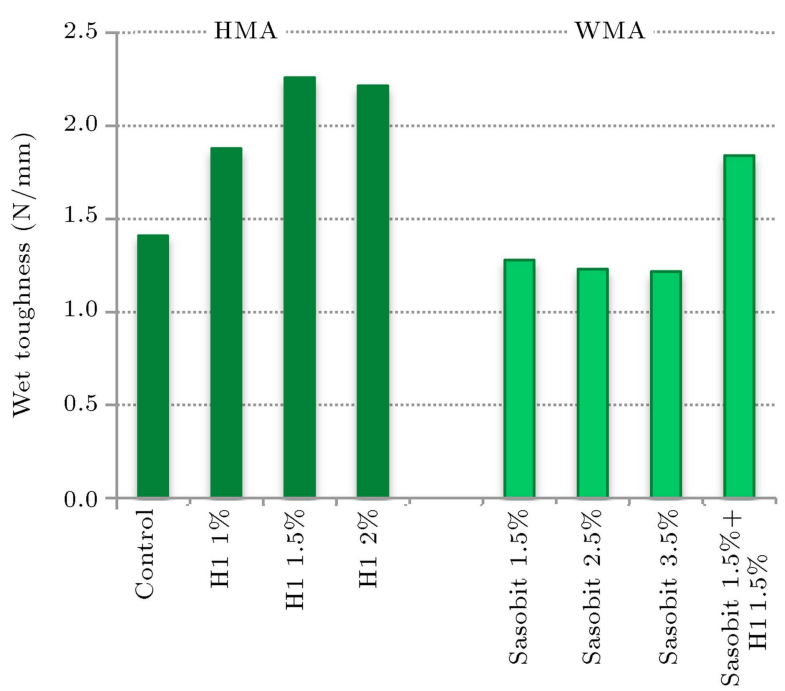

(b)

Figure 7. Results for (a) dry toughness, and (b) wet toughness.

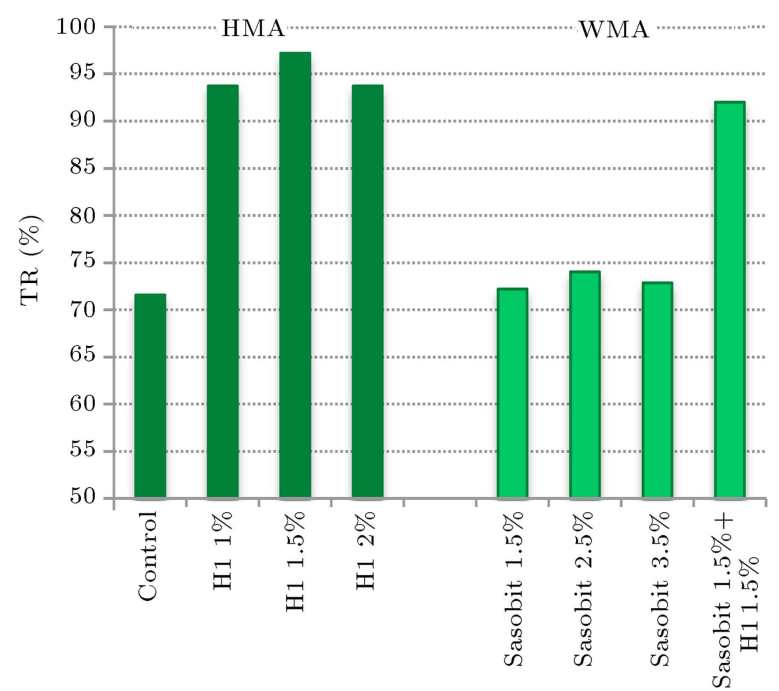

Figure 8. TR results for HMA and WMA. 


\section{Summary and conclusion}

The present study evaluated the moisture susceptibility of WMA mixtures containing Sasobit and the effect of hydrated lime as an anti-stripping agent. The following conclusions can be drawn for the materials tested:

- Moisture resistance in the control HMA and WMA samples (without anti-stripping) was inadequate or only marginally better than the generally accepted minimum value of $80 \%$;

- Mixing and compaction temperatures and aggregate properties such as angularity, roughness, and moisture content play key roles in the aggregate-binder bond and in the resulting ITS, especially in WMA mixtures;

- The TSR indicated that HL was an effective antistripping agent for both HMA and WMA mixtures. The TSR increased as the HL content increased;

- FER and TR analyses yielded results that were similar to the TSR for HMA mixtures, but were different than the results for the WMA mixtures. FER and TR analyses showed a relationship of moisture susceptibility with both the indirect tensile strength and strain resistance of mixtures;

- The TSR, FER, and TR analyses indicated that the use of HL as an anti-stripping agent is required to compensate for the relatively poor moisture resistance of the WMA-Sasobit mixtures, especially where the lower production temperatures for WMA mixtures increase the risk of moisture in the aggregates.

\section{References}

1. Das, A. and Swamy, A.K. "Reclaimed waste materials in sustainable pavement construction", In Climate Change, Energy, Sustainability and Pavements, pp. 419-438, Springer Berlin Heidelberg (2014).

2. Jamshidi, A., Hamzah, M.O. and You, Z. "Performance of warm mix asphalt containing sasobit : Stateof-the-art", Constr. Build. Mater., 38, pp. 530-53 (2013).

3. Lee, S.J., Amirkhanian, S.N., Park, N.W. and Kim, K.W. "Characterization of warm mix asphalt binders containing artificially long-term aged binders", Constr. Build. Mater., 23(6), pp. 2371-9 (2009).

4. Haggag, M.M., Mogawer, W.S. and Bonaquist, R. "Fatigue evaluation of warm mix asphalt mixtures using uniaxial cyclic direct tension compression test", Trans. Res. Rec.: J. Trans. Res. Board, 2208, pp. 2632 (2011).

5. Bonaquist, R. "Mix design practices for warm mix asphalt", NCHRP Report 691, Trans. Res. Board of Natl. Academies, Washington, DC (2011).
6. Bower, N., Wen, H., Wu, S., Willoughby, K., Weston, J. and DeVol, J. "Evaluation of the performance of warm mix asphalt in Washington state", Int. J. of Pave. Engrg., (ahead-of-print), pp. 1-12 (2015).

7. Mallick, R.B. and Bergendahl, J. "A laboratory study on $\mathrm{CO}_{2}$ emission from asphalt binder and its reduction with the use of warm mix asphalt", Int. J. Sustain. Engrg., 2(4), pp. 275-83 (2009).

8. Zhang, J., Yang, F., Pei, J., Xu, S. and An, F. "Viscosity-temperature characteristics of warm mix asphalt binder with Sasobit ${ }^{\circledR} "$, Constr. Build. Mater., 78, pp. 34-39 (2015).

9. West, R., Rodezno, C., Julian, G., Prowell, B., Frank, B., Osborn, L.V. and Kriech, T. "Field performance of warm mix asphalt technologies", NCHRP Report 779, Trans. Res. Board of Natl. Academies, Washington, DC (2014).

10. Lesueur, D., Petit, J. and Ritter, H.J. "The mechanisms of hydrated lime modification of asphalt mixtures: a state-of-the-art review", Int. J. of Road Mater. Pave. Des., 14(1), pp. 1-16 (2013).

11. Little, D.N. and Jones, D.R. "Chemical and mechanical processes of moisture damage in hot-mix asphalt pavements", In: Moisture Sensitivity of Asphalt Pavements, A National Seminar, Trans. Res. Board of Natl. Academies, Washington, DC, pp. 43-76 (2003).

http://onlinepubs.trb.org/onlinepubs/conf/repo rts/moisture_seminar.pdf. Accessed 17 July 2013.

12. Kim, Y.R., Zhang, J. and Ban, H. "Moisture damage characterization of warm-mix asphalt mixtures based on laboratory-field evaluation", Constr. Build. Mater., 31, pp. 204-11 (2012).

13. Martin, A.E., Arambula, E., Yin, F., Cucalon, L.G., Chowdhury, A., Lytton, R. and Park, E.S. "Evaluation of the moisture susceptibility of WMA technologies", NCHRP Report 763, Trans. Res. Board of Natl. Academies, Washington, DC. (2014).

14. Epps, J., Berger, E. and Anagnos, J.N. "Treatments in: Moisture sensitivity of asphalt pavements", $\mathrm{A} \mathrm{Na}$ tional Seminar, Trans. Res. Board of Natl. Academies, Washington, DC, pp. 120-188 (2003). http://onlinepubs.trb.org/onlinepubs/conf/reports/ moisture_seminar.pdf. Accessed 17 July 2013.

15. Souliman, M.I., Piratheepan, M., Hajj, E.Y., Sebaaly, P.E. and Sequeira, W. "Impact of lime on the mechanical and mechanistic performance of hot mixed asphalt mixtures", Int. J. of Road Mater. Pave. Des., 16(2), pp. 421-444 (2015).

16. Witczak, M.W., Kaloush, K., Pellinen, T. and ElBasyouny, M. "Quintus HV: simple performance test for superpave mix design", NCHRP Report 465, Trans. Res. Board of Natl. Academies, Washington, DC (2002).

17. Advanced Asphalt Technologies, LLC "Special mixture design considerations and methods for warm mix asphalt: A supplement to NCHRP report 673, A 
manual for design of hot mix asphalt with commentary", NCHRP Report 714, Trans. Res. Board of Natl. Academies, Washington, DC (2012).

18. Xiao, F. and Amirkhanian, S.N. "Laboratory investigation of moisture damage in rubberized asphalt mixtures containing reclaimed asphalt pavement", Int. J. Pave. Engrg., 10(5), pp. 319-28 (2009).

19. Tarefder, R.A. and Ahmad, M. "Evaluating the relationship between permeability and moisture damage of asphalt concrete pavements", J. of Mater. in Civil Engrg, 27(5) (2015).

20. Tabatabaee, N. and Tabatabaee, H.A. "Multiple stress creep and recovery and time sweep fatigue tests: crumb rubber modified binder and mixture performance", Trans. Res. Rec.: J. Trans. Res. Board, 2180, pp. 6774 (2010).

\section{Biographies}

Hadi Nabizadeh received his BSc degree in Civil Engineering from Ferdowsi University of Mashhad in 2009. He pursued his MSc degree at Sharif University of Technology in the field of Pavement Engineering and performed his thesis research project on the performance properties of hot mix asphalt modified with hydrated lime in 2012. Currently, he is continuing his education as a PhD student at University of Nevada, Reno, and working as a Research Assistant at Western Regional Superpave Center. His area of research is mainly focused on the evaluation of super-heavy loads on flexible pavements.
Behzad Naderi received his BSc degree in Civil Engineering in 2008. He then continued his education as a graduate student in the field of Pavement Engineering at Sharif University of Technology (SUT) and successfully defended his thesis titled "Evaluation of WMA Containing Sasobit" in 2011. He is currently studying as a PhD candidate at Tarbiat Modares University (TMU), Tehran, Iran. His research is focused on predicting fatigue life of asphalt mixtures.

Nader Tabatabaee has been a member of the Civil Engineering Faculty at Sharif University of Technology (SUT) since 1991. He teaches and conducts research on pavement materials and design, particularly on modified asphalts and asphalt mixtures. He received his BSc from the University of California at Berkeley and his MSc and PhD from The Pennsylvania State University. He has published more than 75 peer reviewed publications and conference papers in his field as well as many technical reports for various public and private agencies. He served as Chair of the Department of Civil Engineering at SUT during from 1997 to 2001 and as Dean of Graduate Studies from 2001 to 2006. Dr. Tabatabaee is a founding member of the Civil Engineering Congress in Iran and the Middle East Society of Asphalt Technologists (MESAT) and is a member of TRB, AAPT, ISAP, and RILEM. His areas of research interest include pavement instrumentation, pavement design, maintenance and management, and asphalt technology. 